\title{
Improvment of Mechanical Properties of the Cement Compound in Order to Increase the Degree of Its Filling
}

\author{
Vladimir A. Kulagina, \\ Tatiana A. Kulagina a , Eleonora M. Nikiforova ${ }^{a}$, \\ Dmitriy A. Prikhodov*a,b and Alexander F. Shimanskiya \\ ${ }^{a}$ Siberian Federal University \\ 79 Svobodny, Krasnoyarsk, 660041, Russia \\ ${ }^{b}$ Radiochemical plant Mining and Chemical Combine \\ 53 Lenin Str., Zheleznogorsk, 662972, Russia
}

Received 11.06.2018, received in revised form 28.06.2018, accepted 13.07.2018

Long-term and safe management of radioactive wastes, that was formed as a result of implementation of nuclear weapon programs, still remains a key problem of the nuclear energetics. The technology based on the admixture of liquid radioactive wastes in inorganic hydraulic binders (cementation process) has a number of cogent advantages: the process is of low-temperature, it proceeds without formation of gaseous radioactive wastes and the obtained cement compound provides the safety storage for a long time (more than 106 years). For the purpose to increase the degree of the cement compound filling with the liquid radioactive wastes, the possibility to apply reinforcing fillers was researched, these fillers are multilayered carbon nanotubes (MCNT) and pyrogenic silica (aerosil). It has been revealed that the proportion of MCNT should not exceed $1.5 \%$ by weight of the cement content and the aerosil proportion should not exceed $0.5 \%$ of the binder weight. The expediency of using the effects of cavitation technology in the preparation of the cement compound.

Keywords: radioactive waste, cement compound, multilayered carbon nanotubes, aerosol, cavitational technology.

Citation: Kulagin V.A., Kulagina T.A., Nikiforova E.M., Prikhodov D.A., Shimanskiy A.F. Improvment of mechanical properties of the cement compound in order to increase the degree of its filling, J. Sib. Fed. Univ. Eng. technol., 2018, 11(6), 711-731. DOI: 10.17516/1999-494X-0087.

(C) Siberian Federal University. All rights reserved

This work is licensed under a Creative Commons Attribution-NonCommercial 4.0 International License (CC BY-NC 4.0).

* Corresponding author E-mail address: pramid1985@mail.ru 


\title{
Повышение механических свойств цементного компаунда с целью увеличения степени его наполнения
}

\author{
В.А. Кулагин ${ }^{\mathrm{a}}$, Т.А. Кулагина ${ }^{\mathrm{a}}$, \\ Э.М. Никифорова ${ }^{a}$, Д.А. Приходов ${ }^{\text {a, },}$, А.Ф. Шиманский \\ ${ }^{a}$ Сибирский федеральный университет \\ Россия, 660041, Красноярск, пр. Свободный, 79 \\ ${ }^{\sigma}$ Радиохимический завод Горно-химического комбината \\ Россия, 662972, Железногорск, ул. Ленина, 53
}

\begin{abstract}
Долговременное безопасное обращение с радиоактивными отходами, образовавшимися в результате выполнения ядерных оружейных программ, остается ключевой проблемой для ядерной энергетики на современном этапе. Технология, основанная на включении жидких радиоактивных отходов в неорганические гидравлические вяжущие (процесс цементирования), имеет ряд неоспоримых преимуществ: проиесс является низкотемпературным, протекает без образования газообразных радиоактивных отходов, а полученный иементный компаунд обеспечивает безопасность хранения в течение длительного времени (более $10^{6}$ лет). С иелью увеличения степени наполнения иементного компаунда жидкими радиоактивными отходами исследована возможность применение армирующих наполнителей-многослойных углеродных нанотрубок (МУНТ) и пирогенного кремнезема (аэросила). Установлено, что дозировка МУНТ не должна превымать 1,5\% масс. от содержания цемента, аэросила - 0,5\% масс. от вяжущего. Показана иелесообразность использования эффектов кавитационной технологии при получении цементного компаунда.
\end{abstract}

Ключевые слова: радиоактивные отходы, иементный компаунд, многослойные углеродные нанотрубки, аэросил, кавитационная технология.

\section{Введение}

В России создана собственная правовая и организационная система обеспечения и регулирования ядерной и радиационной безопасности [1-3], соответствующая международным конвенциям, признанным Российской Федерацией $[4,5]$. Существующая в нашей стране система обращения с радиоактивными отходами (РАО) сформировалась в процессе развития в СССР ядерных технологий и в силу этого имеет ряд характерных особенностей, которые отличают ее от других стран $[6,7]$. Технологии обращения с радиоактивными отходами и труднорастворимыми осадками описаны в [8-12], а технологии извлечения с помощью PUREX-процесса - в $[10,11,13-16]$. Наиболее широко используемым в данное время процессом отверждения жидких радиоактивных отходов низкого и среднего уровней активности является включение жидких радиоактивных отходов (ЖРО) в неорганические вяжущие [6, 19-23].

Процесс производства смешанного уран-плутониевого топлива (МОКС-топлива) сопровождается образованием альфа-радиоактивных отходов, требующих особых методов обращения. В таких странах, как США, Германия, Франция, Япония и Бельгия, процесс цементирования относится к традиционным методам иммобилизации радиоактивных, в том числе и альфарадиоактивных, отходов (РАО) [24].

В настоящее время наиболее широко используется процесс цементирования как технология кондиционирования жидких радиоактивных отходов и представляет собой процесс 
иммобилизации ЖРО в цементную матрицу с получением твердого конечного продукта (цементного компаунда), направляемого далее на безопасное длительное хранение. Процесс цементирования заключается в смешении жидких солевых концентратов и пульп с цементом с последующим схватыванием и образованием твердого монолита.

Выбор цементов различных типов для фиксации альфа-радиоактивных отходов обусловлен комплексом уникальных свойств вяжущего компонента. Цементные компаунды прекрасно удерживают актиноиды. Цементы пригодны для кондиционирования твердых отходов и гетерогенных пульп. Они характеризуются высокой термической устойчивостью за счет оптимальной технологии, в том числе низкотемпературного цементирования. Цементный компаунд образован термодинамически стабильными гидратированными солями [25]. Основными требованиями, предъявляемыми к конечным формам отвержденных РАО, являются их достаточная механическая, физическая и химическая стабильность, обеспечивающая безопасность обращения, транспортировку и хранение, а также совместимость упаковки и формы отвержденных отходов с условиями в хранилище, что позволяет свести к минимуму поступление радионуклидов в биосферу [26].

Если принять, что надежность природных и инженерных барьеров хранилища отвержденных упаковок с РАО позволит увеличить допустимое содержание отдельных радионуклидов (прежде всего актиноидов) в отходах, подлежащих отверждению, становится очевидной целесообразность проведения исследований, направленных на увеличение степени наполнения цементного компаунда элементами РАО и оценку влияния повышенного содержания РАО на его качество. Положительный результат исследований приведет к увеличению удельного объема захораниваемых отходов и, следовательно, к снижению расходов на создание и эксплуатацию хранилища отвержденных РАО.

Предельное содержание отдельных радионуклидов в цементном компаунде будет определяться требованиями ядерной безопасности и скоростью выщелачивания наиболее растворимых радионуклидов $\left({ }^{137} \mathrm{Cs},{ }^{90} \mathrm{Sr}\right)$, так как высокая радиационная устойчивость цементной матрицы (обычно цементы устойчивы до 10 МГр [27]) дает основание предположить, что радиационное воздействие не будет являться определяющим фактором в предельном содержании радионуклидов. Повышение содержания трансурановых радионуклидов в цементном компаунде приведет к пренебрежимо малому увеличению поглощенной дозы, несравнимому со значением 10 МГр, и не повлияет на качество цементного компаунда. Для варианта захоронения цементированных РАО в металлических контейнерах материал контейнера будет являться дополнительным защитным барьером.

С точки зрения ядерной безопасности допустимое содержание радионуклидов будет определяться содержанием $\alpha$-излучающих трансурановых элементов, которое должно полностью исключить возможность возникновения самоподдерживающейся цепной реакции деления. Для этого лимитируется содержание $\alpha$-излучающих трансурановых элементов. Для их водных смесей безопасное содержание будет определяться отношением массы плутония к массе природного урана. Ядерно безопасное количество плутония для водных смесей с ураном приведено в таблицах $[28,29]$.

Одним из показателей, обеспечивающих безопасность длительного хранения и захоронения радиоактивных отходов, служит их физико-химическая характеристика. При выборе фор- 
мы захораниваемых отходов следует учитывать не только соответствие ее качества действующим нормативным требованиям, но и экономические факторы.

Для хранения цементного компаунда используются несколько типов контейнеров: невозвратный защитный контейнер (КРАД-1,36; КРАД-1,36Т и КРАД-3,0; НЗК-150-1,5) и стандартная 200-литровая металлическая бочка. В каждом из этих вариантов хранения возможен сильный разогрев цементного компаунда в процессе его твердения.

Результаты исследований [29], посвященных ядерной безопасности при обращении с отходами радиохимических производств, показали, что при использовании для хранения отвержденных материалов контейнеров (бочек) объемом 200 л ядерная безопасность обеспечивается для любых видов отходов, если содержание плутония в упаковке не превышает 50 г, а урана-235- 80 г.

$\mathrm{C}$ точки зрения скорости выщелачивания наиболее растворимых радионуклидов ${ }^{137} \mathrm{Cs}$,

${ }^{90} \mathrm{Sr}$ их надежное закрепление в цементном компаунде обеспечивается введением в матричный материал сорбентов - глин бентонитового класса или цеолитов (например, клиноптилолита). Данные материалы обладают хорошими адсорбционными свойствами, обусловленными высоким (более 70 масс. \%) содержанием глинистого минерала монтмориллонита [30]. Глины, состоящие главным образом из монтмориллонита, на 100 г вещества содержат от 60 до 100 мг-экв обменных катионов [31].

Повышение степени наполнения цементного компаунда может быть получено за счет концентрирования отверждаемой пульпы путем декантации, фильтрации или упаривания. В данной работе наполняемость повышалась за счет «сухого» цементирования (отверждения сухого остатка пульпы).

\section{Материалы и техника эксперимента}

Здесь рассмотрены результаты исследования цементных компаундов с армированием углеродными нанотрубками и получаемые с использованием кавитационной технологии $[32,33]$. Для разработки нового метода обращения с радиоактивными отходами в лаборатории ФГУП «Горно-химический комбинат» произведена серия экспериментальных работ по созданию цементных компаундов. Определялась зависимость их свойств от режима приготовления цементной смеси, подготовки пульпы и свойств используемой воды, которая приготавливалась с применением эффектов гидродинамической кавитации. Методика проведения экспериментов описана в [18]. Основными задачами при выполнении работ являлись:

- проверка влияния физико-химических свойств воды на качество получаемого цементного компаунда;

- проверка влияния ультразвукового воздействия на пульпу перед «включением» ее в цементный компаунд с целью уменьшения размера частиц пульпы и получения более однородного состава.

Изотопный состав и количество радионуклидов в 1 кг пульпы представлены в табл. 1, а в табл. 2 - данные о тепловыделении продуктов деления наиболее гамма-активных изотопов пульпы. Общее тепловыделение от 1 кг пульпы, с учетом всех изотопов составляет $1,68 \cdot 10^{-4}$ Вт [34]. 
Таблица 1. Изотопный состав и количество радионуклидов в 1 кг пульпы

Table 1. Isotopic composition and amount of radionuclides in $1 \mathrm{~kg}$ of pulp

\begin{tabular}{|c|c|}
\hline Концентрация урана, г/кг & $1,0 \cdot 10^{-3}$ \\
\hline Концентрация плутония, г/кг & $2,8 \cdot 10^{-4}$ \\
\hline Америций-241, Бк/кг & $6,628 \cdot 10^{5}$ \\
\hline Стронций-90, Бк/кг & $3,7 \cdot 10^{7}$ \\
\hline Кобальт-60, Бк/кг & $6,668 \cdot 10^{4}$ \\
\hline Цезий-137, Бк/кг & $3,282 \cdot 10^{7}$ \\
\hline Европий-152, Бк/кг & $3,008 \cdot 10^{5}$ \\
\hline
\end{tabular}

Таблица 2. Тепловыделение продуктов деления

Table 2. Heat release of fission products

\begin{tabular}{|c|c|c|c|c|c|}
\hline Нуклид & Масса, г & $\begin{array}{c}\text { Удельная } \\
\text { активность, Бк/г }\end{array}$ & $\begin{array}{c}\text { Активность, } \\
\text { Бк }\end{array}$ & $\begin{array}{c}\text { Удельное } \\
\text { тепловыделение, } \\
\text { Вт/г }\end{array}$ & $\begin{array}{c}\text { Тепловыделение, } \\
\text { Вт }\end{array}$ \\
\hline${ }^{60} \mathrm{Co}$ & $1,59 \mathrm{E}-09$ & $4,19 \mathrm{E}+13$ & $6,66 \mathrm{E}+04$ & $1,74 \mathrm{E}+01$ & $2,77 \mathrm{E}-08$ \\
\hline${ }^{137} \mathrm{Cs}$ & $1,02 \mathrm{E}-05$ & $3,22 \mathrm{E}+12$ & $3,28 \mathrm{E}+07$ & $9,58 \mathrm{E}-02$ & $9,75 \mathrm{E}-07$ \\
\hline${ }^{152} \mathrm{Eu}$ & $3,66 \mathrm{E}-12$ & $8,19 \mathrm{E}+16$ & $3,00 \mathrm{E}+05$ & $1,05 \mathrm{E}+04$ & $3,83 \mathrm{E}-08$ \\
\hline Сумма & - & - & $3,32 \mathrm{E}+07$ & & $1,04 \mathrm{E}-06$ \\
\hline
\end{tabular}

Приготовление компаунда. В соответствии с программой проведения экспериментальных работ по выбору состава цементного компаунда и технологических режимов цементирования для приготовления цементного компаунда использовали:

- портландцемент марки ЦЕМ I 42,5Б, ГОСТ 31108-2003 (по прежней классификации ПЦ 500-Д0), ОАО «Мордовцемент»;

- сорбционную добавку - молотый клиноптилолит Холинского месторождения ТУ 2163 002-12763074 следующего фракционного состава (\% по массе): более 1 мм - 2,55; до 0,5 мм - 13,74; до 0,25 мм - 12,20; до 0,125 мм - 34,19; до 0,1 мм - 15,23; до 0,05 мм - 20,03; менее 0,05 мм - 2,06;

- $\quad$ воду из ППВ (техническую) и дистиллированную воду после кавитационного воздействия;

- $\quad$ нерастворимые остатки гидроксидной пульпы.

Состав цементного раствора корректировался после проведения пробного замеса с использованием приобретенных для проведения опытных операций вяжущих компонентов и определения растекаемости цементного раствора. Для определения растекаемости цементного компаунда использовали прибор Суттарда по ГОСТ 23789-79 «Вяжущие гипсовые. Методы испытаний».

Исследования проводились на пульпах, твердая фаза которых представлена в основном гидроксидами металлов и полимеризованными формами кремниевой кислоты (табл. 3), а также 
Таблица 3. Содержание гидроксидов стабильных металлов в пульпе

Table 3. Content of hydroxides of stable metals in the pulp

\begin{tabular}{|c|c|}
\hline Компонент твердой фазы пульпы & Содержание в пульпе, г/л \\
\hline $\mathrm{Al}(\mathrm{OH})_{3}$ & 11,27 \\
\hline $\mathrm{Fe}(\mathrm{OH})_{3}$ & 27,84 \\
\hline $\mathrm{Cr}(\mathrm{OH})_{3}$ & 2,3 \\
\hline $\mathrm{Mn}(\mathrm{OH})_{2}$ & 38,12 \\
\hline $\mathrm{Ni}(\mathrm{OH})_{2}$ & 14,17 \\
\hline $\mathrm{SiO}_{2}$ & 6,3 \\
\hline
\end{tabular}

Таблица 4. Составы цементных компаундов, масс. \%

Table 4. Formulations cement compounds, by weight. \%

\begin{tabular}{|c|l|c|c|c|}
\hline \multirow{2}{*}{$\begin{array}{c}\text { Индекс типа } \\
\text { компаунда }\end{array}$} & \multirow{2}{*}{ Компоненты компаунда } & \multicolumn{3}{|c|}{ Содержание компонентов } \\
\cline { 2 - 5 } & & Состав А & Состав Б & Состав В \\
\hline \multirow{3}{*}{1} & Портландцемент & 54,6 & 52,9 & 50,2 \\
& Вода & 43,8 & 42,3 & 40,2 \\
& Пульпа & 1,6 & 4,8 & 4,6 \\
\hline \multirow{2}{*}{2} & Портландцемент & 49,9 & 48,6 & 4,7 \\
& Бентонит & 5,0 & 4,9 & 39,0 \\
\hline \multirow{3}{*}{3} & Вода & 43,5 & 41,7 & 9,6 \\
\hline & Пульпа & 54,6 & 4,8 & 5,0 \\
& Портландцемент & 0,4 & 53,2 & 39,0 \\
\hline
\end{tabular}

оксидами марганца и пентаоксидом ниобия, остатками ионообменных смол, ферроцианидами никеля и цезия. Значительная часть трансурановых элементов в пульпе заключена в виде мелкодисперсных частиц диоксидов [35].

В компаунд вводили сухую пульпу из расчета создания степени его наполнения 1,6, 4,8 и 9,6 масс. \%. Приготовление компаундов производилось при водо-вяжущем соотношении (В/В) 0,7-0,9. Состав изготовленных образцов цементных компаундов представлен в табл. 4.

Состав цементного раствора корректировался после проведения пробного замеса с использованием приобретенных для проведения опытных операций вяжущих компонентов и определения растекаемости цементного раствора. Для определения растекаемости цементного компаунда применяли прибор Суттарда по ГОСТ 23789-79 «Вяжущие гипсовые. Методы испытаний».

При изготовлении образцов использовали следующую схему смешивания компонентов: клиноптилолит с гидроксидной пульпой загружали в пластиковые стаканы в заданных соотношениях и перемешивали. Через 15 мин добавляли расчетное количество цемента и воды и полученную смесь тщательно перемешивали, затем заливали в специально изготовленные

$$
-716-
$$


формы из фторопласта для формирования образцов в виде цилиндров диаметром и высотой по 20 мм. Путем легкого постукивания по корпусу форм в течение нескольких минут смесь уплотняли и удаляли из нее воздух. После этого формы с образцами помещали на 24 ч в камеру нормального твердения, обеспечивающую при температуре $20-30{ }^{\circ} \mathrm{C}$ относительную влажность воздуха $95 \pm 5 \%$. Через сутки образцы извлекали из форм и помещали их обратно в камеру нормального твердения на 28 сут. После выдержки образцы испытывали на механическую прочность, водо- и морозостойкость. Для обеспечения сопоставимости и достоверности результатов характеристики образцов определяли по данным трех опытов.

\section{Влияние эффектов кавитации на физико-химические свойства воды (кавитационная технология)}

Для оценки эффективности кавитационной обработки применили ряд физико-химических показателей воды: температура; концентрация растворенного кислорода (КРК); показатель рН; электропроводность; окислительно-восстановительный потенциал (ОВП) и др. Для измерения физико-химических показателей воды использовались анализатор растворенного кислорода «МАРК-201» и 4-параметрический прибор «WaterTest». Основы кавитационного воздействия на обрабатываемые среды описаны в [32, 33].

Обработку проводили в кавитационном миксере с блоком управления и питания [36]. Мощность двигателя составляет 1 кВт, объем рабочей камеры $3 \cdot 10^{-4} \mathrm{M}^{3}$. В качестве рабочего органа использована двухлопастная крыльчатка с клиновидным профилем и углами раскрытия клина от 10 до 90. Рабочие числа оборотов изменялись до 14000 об/мин, что обеспечило получение чисел кавитации до $\chi=0,05$. Схема управления позволяла плавно изменять частоту вращения ротора, поддерживать число оборотов независимо от изменяющейся нагрузки и фиксировать время обработки. В данном случае по результатам предварительного исследования [37] был выбран профиль с углом при вершине клина $20^{\circ}$.

Рассматриваемый феномен механолиза воды лежит в основе специфических свойств и связанных с ними явлений, происходящих в воде, подвергнутой механическому (гидродинамическому) воздействию. Модифицированная в результате гидромеханической обработки (или, как ее еще называют, активированная) вода способна интенсифицировать примерно на $30 \%$ ряд технологических процессов [32, 33, 38]. Здесь под термином «активированная вода» будем иметь в виду общепринятое понятие активной среды, т.е. вещества, в котором распределение частиц (атомов, молекул, ионов) по энергетическим состояниям не является равновесным и хотя бы для одной пары уровней энергии осуществляется инверсия населенности.

Активация твердых и жидких систем, приводящая к изменению их физических и химических свойств, реакционной способности, дефектной (примесной) структуры и т.п., может быть осуществлена различными внешними воздействиями: слабыми и сильными. К таким воздействиям можно, в частности, отнести механическую, магнитную, ультразвуковую обработку, радиационное воздействие (например, облучение гамма-квантами и ионными пучками), а также термообработку. Методы активации можно подразделить на методы, разрушающие образцы в целом (диспергация) и не разрушающие, а изменяющие только дефектную структуру. 
Исследования гидромеханической обработки воды (как достаточно сильного воздействия) показали, что последующая активность воды проявляется как в макромасштабе, так и на микроуровнях (на молекулярном уровне и субмолекулярном).

Суть гидродинамического воздействия может быть сведена к действию двух механизмов: распространению ударных волн вблизи схлопывающегося кавитационного микропузырька и ударному действию кумулятивных микроструек при несимметричном коллапсе кавитационных микропузырьков. Причем в данном контексте способ получения кавитационных микропузырьков не имеет значения. Этим основным механизмам сопутствует повышение температуры и давления вблизи пузырька, делая локальную область около него уникальным реактором для проведения различных реакций и процессов, что и легло в основу кавитационной технологии [32]. На сегодняшний день кавитационная обработка воды является наименее затратной - примерно 0,65 кВт/м ${ }^{3}[32,38]$.

Результаты экспериментальных исследований изменения характеристик дистиллированной воды после кавитационной обработки с постоянным числом кавитации $\chi=0,05$ и методы регрессионного анализа позволили установить рациональную продолжительность кавитационной обработки. Динамика поведения ОВП в процессе кавитационной обработки воды представлена на рис. 1. График построен по экспериментальным точкам, усредненным по 5-10 измерениям, относительная ошибка определения ОВП - 2 \%. Зависимость ОВП от времени кавитационного воздействия носит экспоненциальный характер:

$$
y=15,34 \exp (-x / 106,36)+15,34 \exp (-x / 106,39)+149,24 \exp (-x / 21,28)+141,43
$$

и при значении 150 с выходит на плато, что позволяет выделить участок наиболее интенсивного изменения ОВП - 30-90 с. При кавитационном воздействии на воду в течение этого времени ОВП понижается на $43 \%$, тогда как максимальное понижение ОВП составляет $47 \%$. То есть скорость изменения ОВП при кавитационном воздействии в диапазоне 30-90 с почти в три раза

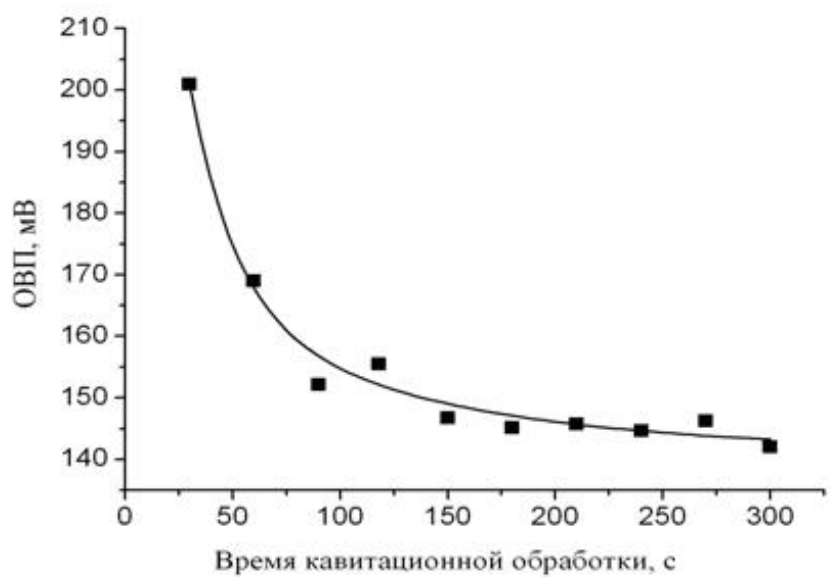

Рис. 1. Зависимость ОВП дистиллированной воды от времени кавитационной обработки. ОВП исходного дистиллята $264 \mathrm{MB}$

Fig. 1. Dependence of ORP of distilled water on the time of cavitation treatment. ORP of the original distillate $264 \mathrm{mV}$ 
Таблица 5. Физико-химические показатели воды до и после кавитационной обработки

Table 5. Physicochemical parameters of water before and after cavitation treatment

\begin{tabular}{|c|c|c|c|c|c|c|c|c|c|c|}
\hline $\begin{array}{c}\text { Объем } \\
\text { заполнения СК- } \\
\text { реактора } V, \%\end{array}$ & \multicolumn{2}{|c|}{$T,{ }^{\circ} \mathrm{C}$} & \multicolumn{2}{|c|}{ КРК, \% нас } & \multicolumn{2}{c|}{$S$, Ом$^{-1} / \mathrm{cm}$} & \multicolumn{2}{|c|}{$\mathrm{pH}$} & \multicolumn{2}{c|}{$E, \mathrm{MB}$} \\
\hline $\begin{array}{c}\text { Параметры } \\
\begin{array}{c}\text { воды } \\
\text { до обработки }\end{array}\end{array}$ & \multicolumn{2}{|c|}{20,7} & \multicolumn{2}{|c|}{101,2} & \multicolumn{2}{|c|}{0} & \multicolumn{2}{|c|}{5,4} & \multicolumn{2}{|c|}{200} \\
\hline 100 & 40,5 & 32,6 & 85,1 & 96,65 & 14,5 & 6 & 5,65 & 5,45 & 133 & 168,5 \\
\hline 65 & 34,6 & 27,2 & 87,65 & 95,7 & 5,5 & 13 & 6,0 & 5,7 & 128,5 & 147 \\
\hline
\end{tabular}

Примечание: КРК - концентрация растворенного кислорода; $\alpha$ - угол при вершине клиновидного кавитатора СКреактора; Е - окислительно-восстановительный потенциал; $\mathrm{S}$ - электропроводность.

превышает скорость изменения ОВП при воздействии в диапазоне 90-300 с. Кавитационная обработка воды проводилась при 100 - и 65\%-ном заполнении реактора (табл. 5).

В работах $[38,39]$ установлено, что при воздействии на воду полей высоких давлений (до 1000 МПа) и температур (до $15000^{\circ} \mathrm{C}$ ), образующихся при схлопывании кавитационных микропузырьков, возникает явление механотермолиза - в воде инициируются механохимические реакции с образованием $\mathrm{O}_{2}, \mathrm{H}_{2}, \mathrm{H}_{2} \mathrm{O}_{2}, \mathrm{OH}^{-}$(в ходе рекомбинации радикалов), в результате деструкции образуются свободные водородные связи, возникает явление хемилюминесценции, что, в свою очередь, влечет за собой изменение электропроводности, поверхностного натяжения, кислородосодержания и рН среды; время релаксации указанных свойств до 7-10 сут позволяет использовать их в различных технологических процессах на месте или транспортировать на любые расстояния.

Протекание описанных реакций объясняет интенсивное разрушение материалов, подвергающихся воздействию кавитации, за счет параллельно развивающихся процессов кавитационной эрозии и химической коррозии, находящихся в тесной взаимосвязи. Таким образом, под действием кавитации в водном растворе возможно осуществление разнообразных химических реакций. Кавитационное инициирование их сводится к ионизации и возбуждению молекул воды, благородных и активных газов, а также к диссоциации молекул воды. Каждый из этих процессов осуществляется за время $t \sim 10^{-14}$ с [39]. Продолжительность конечной стадии коллапса пузырька $t \sim 10^{-9}-10^{-8} \mathrm{c}$.

Наряду с указанными в кавитационной полости протекают реакции трансформирования радикалов с участием химически активных газов и рекомбинации радикалов за время $t \sim 10^{-7}-10^{-6}$ с. В результате этих процессов после схлопывания кавитационного пузырька в раствор переходят продукты радикального разложения молекул $\mathrm{H}_{2} \mathrm{O}$ и рекомбинации радикалов, обнаруженные с помощью метода спиновых ловушек, что приводит к накоплению в воде молекулярного $\mathrm{O}_{2}, \mathrm{H}_{2} \mathrm{O}_{2}$ и других соединений. Высокая скорость протекания реакций свидетельствует о том, что они происходят непосредственно в зоне кавитационных разрушений, интенсифицируя процесс кавитационной эрозии, что существенно важно при эксплуатации различного гидро- и энергооборудования, а также в случае диспергирования различных материалов (например, цементного камня). Вода, обладающая такими свойствами,

$$
-719-
$$


Таблица 6. Характеристики используемой воды

Table 6. Characteristics of used water

\begin{tabular}{|c|c|c|}
\hline \multirow{2}{*}{ Образец воды } & \multicolumn{2}{|c|}{ Значение показателя } \\
\cline { 2 - 3 } & $\mathrm{pH}$ & солесодержание, мг/л \\
\hline Вода из ППВ & 7,5 & 310 \\
\hline \multicolumn{2}{|c|}{ Вода, обработанная с использованием эффектов кавитации } \\
\hline Образец № 1 & 7,8 & 3,01 \\
\hline Образец № 2 & 7,7 & 2,64 \\
\hline Образец № 3 & 7,6 & 0,65 \\
\hline
\end{tabular}

Таблица 7. Исходная механическая прочность цементных компаундов

Table 7. Initial mechanical strength of cement compounds

\begin{tabular}{|c|c|c|c|c|c|c|c|}
\hline \multicolumn{2}{|c|}{ Показатель } & \multicolumn{5}{|c|}{ Механическая прочность компаунда через 28 сут, МПа } \\
\hline \multirow{2}{*}{ В/Ц } & \multirow{2}{*}{ В/В } & \multicolumn{2}{|c|}{ С пром. водой } & \multicolumn{2}{|c|}{ Образцы с кавитационно обработанной водой } \\
\cline { 3 - 8 } & \multirow{2}{*}{0.5} & \multirow{2}{*}{0.41} & 36,0 & 32,5 & 27,4 & 27,7 & \multicolumn{2}{|c|}{ № 1} & \multicolumn{2}{|c|}{ № 3} \\
\cline { 3 - 8 } & & \multicolumn{2}{|c|}{ Средн. 34,2 } & \multicolumn{2}{|c|}{ Средн. 27,5 } & Средн. 42,2 & Средн. 47,6 \\
\hline
\end{tabular}

Примечание: В/Ц - водоцементное отношение; В/В - водовяжущее отношение В/В = В/(Ц + $K$-фактор): $K$-фактор определяется при введении тонкого заполнителя по соответствующим нормативным документам.

способствует растворению труднорастворимых материалов $[32,38]$. Характеристики используемой воды приведены в табл. 6.

\section{Результаты экспериментов и их обсуждение}

Испытания на механическую прочность. Механическую прочность образцов определяли по отраслевой инструкции «Цементные компаунды на основе радиоактивных отходов. Определение предела прочности на сжатие на испытательной машине марки TESTING OИ 001.7252011». Предел прочности цементных компаундов определялся по максимальной нагрузке, которую образец выдерживает, не разрушаясь. Механические испытания на сжатие (ГОСТ 310.4) проводили на гидравлическом прессе ВМ-3,4 с погрешностью измерения $\pm 1 \%$. При выполнении измерений соблюдали следующие условия: температура воздуха $(22 \pm 5){ }^{\circ} \mathrm{C}$; относительная влажность воздуха не более 80 \%; атмосферное давление от 84,0 до 106,7 кПа. Результаты механических испытаний представлены в табл. 7.

Видно, что снижение солесодержания с 3,01 до 0,65 мг/л приводит к увеличению механической прочности с 27,5 до 47,6 МПа, однако при этом изменяется показатель рН с 7,8 до 7,6 (табл. 6,7$)$. Поэтому нельзя сделать однозначный вывод о влиянии солесодержания на прочностные характеристики цементных компаундов. Этот вопрос требует отдельного исследования с учетом всех сопутствующих факторов. Тем не менее, опираясь на результаты предыдущих исследований $[38,39]$, есть основание полагать, что в данном случае определяющую роль 
играет повышенная растворяющая способность модифицированной в результате кавитационной обработки воды, способствующая химической гомогенизации и диспергации ЖРО [10-12, 38].

Испытания на морозостойкость. Испытания на морозостойкость проводили по отраслевой инструкции «Цементные компаунды. Определение морозостойкости. Методика проведения испытаний ОИ 001.730-2011» (ГОСТ 10060-2012). Методика испытаний предназначена для определения морозостойкости цементных компаундов, в том числе содержащих радиоактивные отходы. В условиях длительного хранения цементная матрица может быть подвержена совместному воздействию знакопеременных температур и водной среды. Для оценки качества цементных компаундов необходимо сравнение прочности на сжатие образцов, подвергнутых переменному замораживанию и оттаиванию, и контрольных образцов с эквивалентным временем твердения.

Под морозостойкостью понимают способность цементных компаундов сохранять физикомеханические свойства (прочность на сжатие) при многократном переменном замораживании и оттаивании. Как правило, замораживание циклами заметно снижает стойкость бетона за счет нарушения его структуры, уменьшающего прочность [19]. Согласно требованиям ГОСТ Р 51883-2002, цементные компаунды считаются морозостойкими, если их прочность на сжатие после испытаний составляет не менее 5 МПа. Морозостойкость определяли путем сравнения механической прочности образцов, прошедших 30 циклов попеременного замораживания и оттаивания, с их исходной прочностью. Морозостойкость компаунда считается удовлетворительной, если прочность образцов, прошедших испытания, составляет не менее $75 \%$ от исходной прочности (но не ниже допустимых 5 МПа). Для определения морозостойкости использовали шкаф холодильный типа «Ларь» ШН(L)Y-0,175 «Бирюса-200К-5».

Образцы цементного компаунда помещали в сетчатый контейнер. Контейнер погружали в ванну с дистиллированной водой при температуре $(20 \pm 2)^{\circ} \mathrm{C}$. Через 96 ч контейнер извлекали из ванны, помещали его в морозильную камеру и выдерживали в ней при температуре минус $18{ }^{\circ} \mathrm{C}$ в течение 2 ч. После выдержки в морозильной камере образцы извлекали и помещали в вытяжной шкаф на 2 ч. После оттаивания образцы визуально осматривали и фиксировали изменения. Испытания повторяли 30 циклов. Результаты отражены в табл. 8.

Определение скорости выщелачивания. Одним из основных факторов, определяющих надежность длительного хранения и захоронения радиоактивных отходов, является скорость выщелачивания радионуклидов. Согласно ГОСТ Р 51883-2002 скорость выщелачивания радионуклидов (цезия-137 и стронция-90) из цементной матрицы не должна превышать $1 \cdot 10^{-3} \mathrm{r} /\left(\mathrm{cm}^{2} \cdot\right.$ сут). В связи с отсутствием в составе пульпы значимого количества стронция-90 и технической сложностью его определения скорость выщелачивания определяли по цезию-137. Определение скорости выщелачивания проводили по ГОСТ Р 52126-2003. Подготовленные образцы извлекали из камеры нормального твердения, помещали в пластиковые стаканы и заливали 50 мл дистиллированной воды. Отношение объема контактного раствора к поверхности образца составляло 2,65. Стаканчики закрывали крышками для предотвращения испарения воды и оставляли в вытяжном шкафу.

Через $1,3,7,10,14,21,28$ и 56 сут контактный раствор сливали и направляли на анализ, а образцы заливали новой порцией дистиллированной воды. В контактной воде определяли

$$
-721-
$$


Таблица 8. Результаты испытаний образцов цементного компаунда на морозостойкость

Table 8. Test results of samples of cement compound on frost resistance

\begin{tabular}{|c|c|c|c|c|c|}
\hline № & $\begin{array}{c}\text { Исходная механическая } \\
\text { прочность компаунда на } \\
\text { сжатие, МПа }\end{array}$ & $\begin{array}{c}\text { Среднее } \\
\text { значение, } \\
\text { МПа }\end{array}$ & $\begin{array}{c}\text { Прочность компаунда } \\
\text { после испытаний на } \\
\text { морозостойкость, МПа }\end{array}$ & $\begin{array}{c}\text { Среднее } \\
\text { значение, } \\
\text { МПа }\end{array}$ & $\begin{array}{c}\text { Изменение } \\
\text { механической } \\
\text { прочности, \% }\end{array}$ \\
\hline $0-1$ & 36,0 & \multirow{2}{*}{34,2} & 32,8 & \multirow{2}{*}{29,8} & \multirow{2}{*}{$-12,9$} \\
\hline $0-2$ & 32,5 & & 26,8 & & \\
\hline $1-1$ & 27,4 & \multirow{2}{*}{27,5} & 21,3 & \multirow{2}{*}{21,6} & \multirow{2}{*}{$-21,5$} \\
\hline $1-2$ & 27,7 & & 22,0 & & \\
\hline $2-1$ & 39,2 & \multirow{2}{*}{42,2} & 50,7 & \multirow{2}{*}{42,4} & \multirow{2}{*}{0,5} \\
\hline $2-2$ & 45,2 & & 34,1 & & \\
\hline $3-1$ & 52,2 & \multirow{2}{*}{47,6} & 52,9 & \multirow{2}{*}{48,4} & \multirow{2}{*}{1,7} \\
\hline $3-2$ & 43,0 & & 44,0 & & \\
\hline
\end{tabular}

концентрацию цезия-137 по методикам, принятым на ФГУП ФЯО «ГХК». Испытания проводили до установления постоянного значения скорости выщелачивания, которое рассчитывали по формуле

$$
R_{n}=\frac{a_{n}}{A_{0} \cdot S \cdot \tau_{n}},
$$

где $R_{n}$ - скорость выщелачивания цезия-137, г/(см².сут.); $\alpha_{n}$ - активность цезия-137, перешедшего в воду за время $\tau_{n}$, Бк; $A_{0}-$ удельная активность цезия-137 в образце, Бк/г; $S$ - площадь открытой геометрической поверхности образца, находящейся в контакте с водой, $\mathrm{cm}^{2} ; \tau_{n}-$ продолжительность $n$-го периода выщелачивания, сут. Результаты измерения скорости выщелачивания цезия-137 (с использованием кавитационной технологии) представлены в табл. 9 и указывают на то, что она не превышает установленных значений, принятых в атомной отрасли в докуменTax.

Увеличение удельной поверхности цемента непосредственно в водной среде с помощью кавитационного диспергирования позволяет полнее использовать его потенциальные свойства и повышать степень гидратации и поверхностную энергию частиц. Разрушая малопрочную первичную алюминатную крупнозернистую структуру, удается получить мелкокристаллическую структуру цементного камня, прочность которого возрастает в 2-3 раза по сравнению с приготовлением раствора в обычных смесителях.

В процессе обработки цементного молочка образуется «игольчатая» структура цементного камня, которая изменяет ход кристаллохимической реакции твердения бетона, играет роль центров направленной кристаллизации, что приводит, с одной стороны, к появлению фибриллярного строения цементного камня, а с другой - к появлению упрочняющей структурноориентированной надмолекулярной структуры.

Графическая зависимость механической прочности от содержания гидроксидной пульпы в цементных компаундах после 28 сут нормального твердения изображена на рис. 2. Уже при первом добавлении пульпы (составы А) (см. табл. 4) наблюдается снижение прочности для всех типов образцов в два раза по отношению к чистому вяжущему, так как добавление наполни- 
Таблица 9. Скорость выщелачивания цезия-137

Table 9. Leaching rate of $\mathrm{Cs}-137$

\begin{tabular}{|c|c|c|c|c|c|c|c|c|c|}
\hline \multirow{3}{*}{$\begin{array}{c}\text { № } \\
\text { образца }\end{array}$} & \multirow{3}{*}{$A_{0}$, Бк/г } & \multicolumn{8}{|c|}{$R_{n}, \Gamma /\left(\mathrm{cm}^{2} \cdot\right.$ сут $)$} \\
\hline & & \multicolumn{8}{|c|}{ Количество сут } \\
\hline & & 1 & 3 & 7 & 10 & 14 & 21 & 28 & 56 \\
\hline $0-1$ & 5850 & $1,03 \cdot 10^{-2}$ & $2,47 \cdot 10^{-3}$ & $2,93 \cdot 10^{-4}$ & $2,00 \cdot 10^{-4}$ & $1,88 \cdot 10^{-4}$ & $1,26 \cdot 10^{-4}$ & $9,46 \cdot 10^{-5}$ & $4,89 \cdot 10^{-5}$ \\
\hline $0-2$ & 980 & $9,4 \cdot 10^{-2}$ & $2,78 \cdot 10^{-2}$ & $3,04 \cdot 10^{-4}$ & $2,1 \cdot 10^{-4}$ & $1,55 \cdot 10^{-4}$ & $1,33 \cdot 10^{-4}$ & $9,01 \cdot 10^{-5}$ & $5,67 \cdot 10^{-5}$ \\
\hline $1-1$ & 1840 & $6,12 \cdot 10^{-2}$ & $1,51 \cdot 10^{-2}$ & $2,01 \cdot 10^{-3}$ & $1,13 \cdot 10^{-3}$ & $8,08 \cdot 10^{-4}$ & $5,77 \cdot 10^{-4}$ & $4,95 \cdot 10^{-4}$ & $2,52 \cdot 10^{-4}$ \\
\hline $1-2$ & 3840 & $6,69 \cdot 10^{-2}$ & $3,29 \cdot 10^{-2}$ & $1,87 \cdot 10^{-3}$ & $1,16 \cdot 10^{-3}$ & $8,47 \cdot 10^{-4}$ & $5,83 \cdot 10^{-4}$ & $5,09 \cdot 10^{-4}$ & $2,34 \cdot 10^{-4}$ \\
\hline $2-1$ & 2050 & $5,07 \cdot 10^{-2}$ & $2,82 \cdot 10^{-2}$ & $1,83 \cdot 10^{-3}$ & $1,45 \cdot 10^{-3}$ & $7,0 \cdot 10^{-4}$ & $6,18 \cdot 10^{-4}$ & $5,23 \cdot 10^{-4}$ & $2,55 \cdot 10^{-4}$ \\
\hline $2-2$ & 3150 & $7,95 \cdot 10^{-2}$ & $4,36 \cdot 10^{-2}$ & $2,16 \cdot 10^{-3}$ & $1,67 \cdot 10^{-3}$ & $7,31 \cdot 10^{-4}$ & $6,62 \cdot 10^{-4}$ & $5,18 \cdot 10^{-4}$ & $2,71 \cdot 10^{-4}$ \\
\hline $3-1$ & 3680 & $7,34 \cdot 10^{-2}$ & $3,78 \cdot 10^{-2}$ & $2,86 \cdot 10^{-3}$ & $1,91 \cdot 10^{-3}$ & $1,81 \cdot 10^{-3}$ & $7,97 \cdot 10^{-4}$ & $6,96 \cdot 10^{-4}$ & $3,20 \cdot 10^{-4}$ \\
\hline $3-2$ & 1400 & $1,22 \cdot 10^{-1}$ & $6,07 \cdot 10^{-2}$ & $3,45 \cdot 10^{-3}$ & $2,13 \cdot 10^{-3}$ & $1,74 \cdot 10^{-3}$ & $8,41 \cdot 10^{-4}$ & $7,19 \cdot 10^{-4}$ & $3,57 \cdot 10^{-4}$ \\
\hline
\end{tabular}

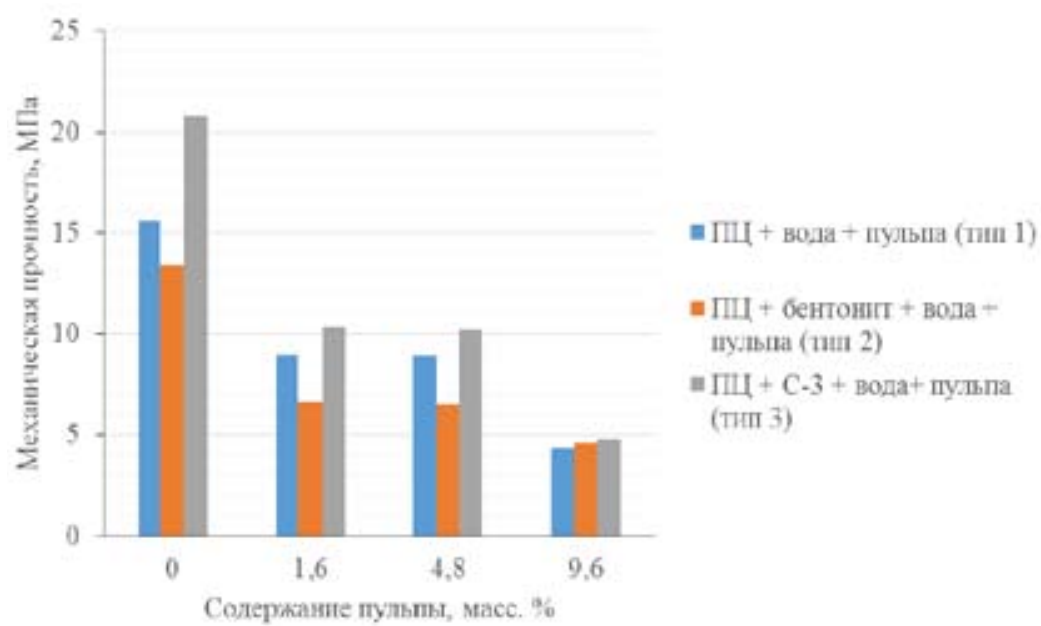

Рис. 2. Зависимость механической прочности образцов цементного компаунда от содержания пульпы

Fig. 2. Dependence of mechanical strength of samples of cement compound on the content of pulp

теля (пульпы) вызывает при сохранении водо-вяжущего соотношения разбавление вяжущего. Последнее приводит к снижению смачиваемости поверхности частиц цемента и снижению его прочности [40]. Дальнейшее увеличение содержания пульпы вызывает еще больший дефицит вяжущего и в конечном итоге падение прочности ниже регламентированного значения (4,9 МПа) при увеличении степени наполнения до 9,6 масс. \% (составы В).

Поверхностные явления, протекающие на границе раздела фаз, оказывают влияние на структуру и свойства граничных слоев вяжущего вещества. Интенсивность указанных процессов регулируется введением различных поверхностно-активных веществ (ПАВ), изменяющих условия смачивания поверхности наполнителя и адгезионную прочность на границе раздела фаз [40]. Таким образом, увеличение механической прочности для образцов типа 3 (табл. 4) объясняется введением в их состав суперпластификатора $C-3$, который за счет взаимодействия 
молекул ПАВ с ионами кальция на поверхности зерен цемента и образования поверхностной пленки соединения типа $-\mathrm{Si}-\mathrm{O}-\mathrm{Ca}-\mathrm{SO}_{3} \mathrm{R}$ приводит к снижению внутреннего трения в бетонной смеси. Кроме того, добавка $C-3$ обладает пептизирующим действием, которое, препятствуя образованию флоккул из цементных частиц в процессе гидратации, вызывает увеличение удельной поверхности частиц и оказывает положительное влияние на интенсивность процессов гидратации и структурообразования цементного камня.

Добавка бентонита (тип 2) приводит к дополнительному разбавлению портландцемента и, следовательно, еще большему уменьшению доли вяжущего вещества в компаунде, что вызывает уменьшение механической прочности по сравнению с компаундом без каких-либо добавок (тип 1).

Для повышения прочности цементного компаунда при увеличении степени его наполнения пульпой было предложено применение армирующих наполнителей, которые при малом добавлении вызывали бы значительные структурные изменения композиционного материала.

Из всего многообразия высокоэффективных химических и минеральных добавок в последнее время большой практический интерес проявляется к нанодобавкам [41-45]. Развитая удельная поверхность, обусловленная малым размером частиц, придает им заметную химическую активность и позволяет отнести их к суперпуццоланам. Количество углеродных нанодобавок фуллероидного типа (однослойные и многослойные углеродные нанотрубки), которое необходимо для модифицирования свойств бетона, составляет порядка 5,0 \% от массы цемента [42]. Углеродные нанотрубки представляют собой молекулы цилиндрической формы, которые состоят из свернутой графитовой плоскости диаметром от 0,8 до 5,0 нм (рис. 3) [43].

Зависимость прочности цементных компаундов от количества добавленных многослойных углеродных нанотрубок (МУНТ) представлена на рис. 4. Испытанию на прочность при сжатии подвергались образцы цементного компаунда. Содержание нанотрубок составляло до 5,5 \% масс. от содержания цемента. Из рис. 4 следует, что механическая прочность возрастает на 37 \% при добавлении 1,5 \% масс. нанотрубок углерода.

Улучшение механических свойств в материалах за счет применения углеродных нанотрубок объясняется с позиции рассмотрения двух эффектов. Во-первых, интенсивное взаимодействие частиц наноразмерного наполнителя с материалом цементной матрицы стимулиру-

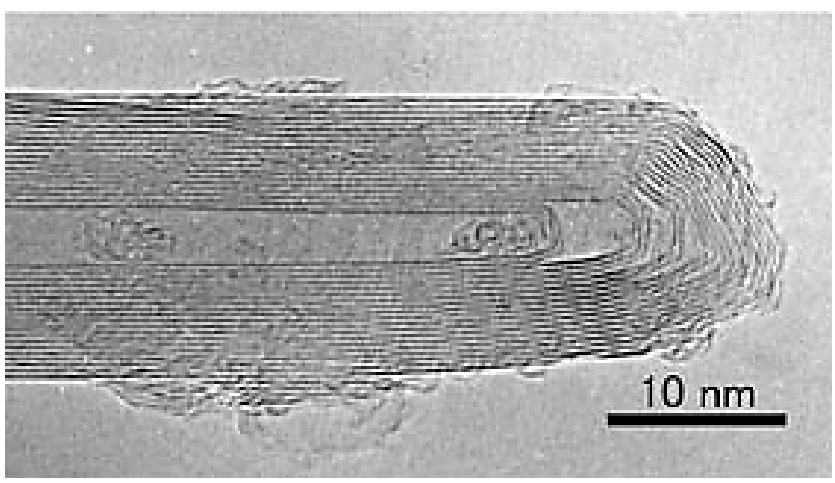

Рис. 3. Электронная микрофотография многослойной углеродной нанотрубки

Fig. 3. Electron micrograph of a multilayer carbon nanotube

$$
-724-
$$




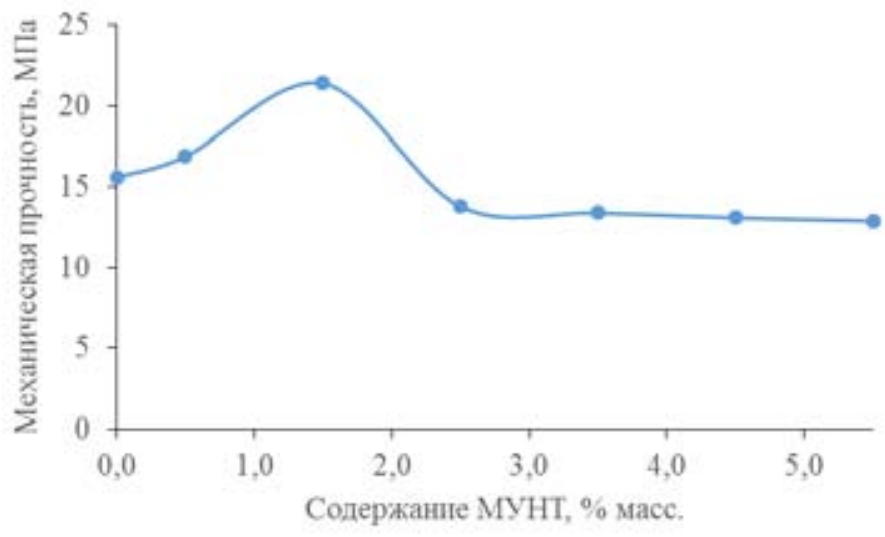

Рис. 4. Механическая прочность образцов цементного компаунда в зависимости от количества добавленных многослойных углеродных нанотрубок

Fig. 4. Mechanical strength of cement compound samples depending on the number of multilayered carbon nanotubes added

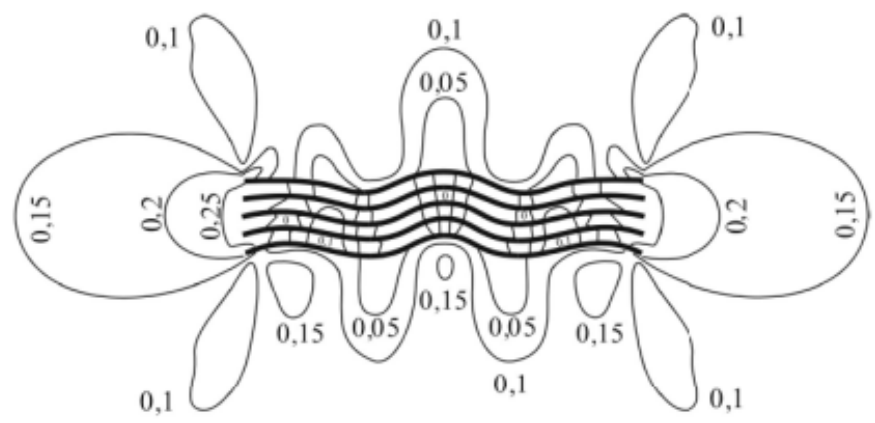

Рис. 5. Распределение механических напряжений в пространстве вокруг нанотрубки углерода

Fig. 5. Distribution of mechanical stresses in the space around a carbon nanotube

ет возникновение значительно большего числа центров (зародышей) кристаллизации, что в конечном итоге приводит к формированию материала со значительно более высокой степенью кристалличности или же к образованию материала с мелкокристаллической структурой, способствуя тем самым более высокой механической прочности материала [44]. Во-вторых, вытянутый характер нанотрубок влечет за собой возникновение в твердеющем материале асимметричных полей напряжений (рис. 5), присутствие которых приводит к образованию в структуре матрицы ориентированных кластеров, сиботаксических групп и кристаллических группировок макромолекул [45].

Наблюдаемое на рис. 4 снижение прочности при добавлении нанотрубок углерода более 1,5 \% масс. вызвано нехваткой вяжущего для высокоразвитой поверхности углеродных нанотрубок. Высокая поверхностная энергия многослойных нанотрубок углерода приводит к образованию глобул, которые трудно равномерно распределить в водной среде и требуются специальные технологии по их диспергированию (ультразвуковые, кавитационные и т.д.). 


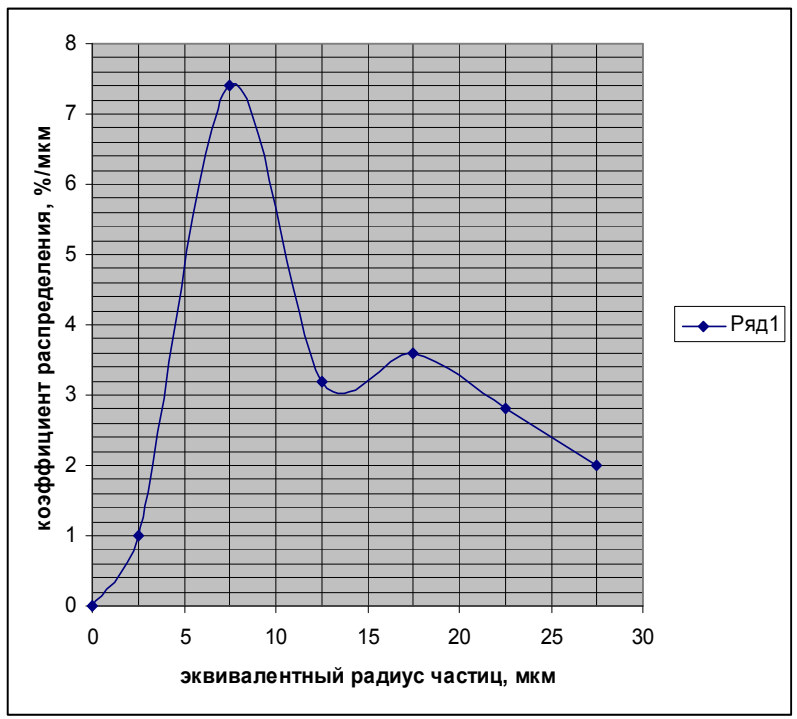

Рис. 6. Дифференциальная кривая распределения пульпы после шести циклов обработки ультразвуком Fig. 6. Differential curve of pulp distribution after six ultrasound processing cycles

На рис. 6 представлена дифференциальная зависимость распределения пульпы после шести циклов обработки ультразвуком. Седиментационный анализ показал, что с увеличением количества циклов обработки пульпы ультразвуком радиус частиц пульпы уменьшается. Так, согласно дифференциальных кривых распределения, если в исходной пульпе преобладали частицы с радиусом 50 мкм, то после двух циклов обработки пульпы ультразвуком преобладают частицы радиусом 20 мкм. После четырех - практически все частицы имели размер 20 мкм. А после шести - преобладают частицы с радиусом до 10 мкм. При использовании ультразвукового воздействия на пульпу ЖРО перед включением ее в цементный компаунд, а также применении кавитационно активированной воды в процессе приготовления цементного компаунда возможно увеличить включение среднеактивных отходов в цементную матрицу до 10 \%.

\section{Выводы}

Установлено, что механическая прочность цементного компаунда не зависит от содержания отдельных радионуклидов, а зависит прежде всего от содержания отходов радиохимических производств (пульпы). При повышении содержания РАО в компаунде его прочность будет определяться долей вяжущего материала. Применение различных модифицирующих добавок приводит к дополнительному уменьшению доли вяжущего в компаунде и снижению его прочности.

Предложенные к применению углеродные нанодобавки фуллероидного типа (многослойные углеродные нанотрубки) позволили добиться повышения прочности компаунда на 37 \% при добавлении их всего 0,5 \% от массы цемента при использовании механического диспергирования. Вместе с тем необходимо продолжение исследований по влиянию добавления МУНТ в компаунд при повышении содержания в нем пульпы на скорость выщелачивания, морозостойкость и устойчивость к длительному пребыванию в воде. 
Полученные данные по иммобилизации радиоактивных отходов в цементную матрицу [21-23] подтверждают существенное влияние кавитационно активированной воды на характеристики цементного компаунда в процессе его приготовления. Применение эффектов кавитации при компаундировании отходов радиохимического производства приводит к повышению прочности цементного камня в 2-3 раза по сравнению с приготовлением раствора обычным способом. Использование эффектов кавитационной технологии целесообразно при утилизации отходов радиохимического производства и приводит к повышению прочности цементного компаунда, устойчивости к термическим циклам (морозостойкости). При этом скорости выщелачивания радионуклидов из цементной матрицы не превышают установленных значений, принятых в нормативных документах атомной отрасли. Последняя характеристика является одним из основных факторов, определяющих надежность длительного хранения и захоронения радиоактивных отходов.

С увеличением количества циклов ультразвуковой обработки радиус частиц пульпы уменьшается от 50 мкм в исходном образце до 10 мкм после шести циклов. Использование предлагаемых методов обращения с радиоактивными отходами позволяет увеличить эффективность их утилизации практически в два раза за счет синергетического эффекта диспергации труднорастворимых осадков и цементного камня, а также образование более прочной структуры цементного компаунда. Вследствие мощного кавитационного воздействия на воду (реализуются поля высоких температур до $15000{ }^{\circ} \mathrm{C}$ и давлений до 10000 атм.), сопровождающегося интенсивным турбулентным микроперемешиванием, механотермолизом воды и т.д. В процессе обработки цементного молочка образуется «игольчатая» структура цементного камня, которая изменяет ход кристаллохимической реакции твердения бетона, играет роль центров направленной кристаллизации, что приводит, с одной стороны, к появлению фибриллярного строения цементного камня, a, с другой - к появлению упрочняющей структурноориентированной надмолекулярной структуры.

Исследование выполнено при финансовой поддержке РФФИ, Правительства Красноярского края в рамках научных проектов №№ 17-48-240386, 18-48-242001 и 18-41-242004.

\section{Список литературы}

[1] Об использовании атомной энергии: Федер. Закон РФ от 21.11 .95 № 170-Ф3 (ред. от 02.07.2013 с изменениями, вступившими в силу 02.09.2013) [Federal Law of the Russian Federation of 21.11.95 "On Use of Nuclear Energy" No. 170 (edition from 07.02.2013 with the changes which have come into force 09.02.2013) (in Russian)].

[2] Безопасность России. Правовые, сочиально-экономические и научно-технические аспекты. Регулирование ядерной и радиационной безопасности. Колл. авт. М.: МГОФ «Знание», НТЦ ЯРБ, 2003. 400 с. [Safety of Russia. Legal, socio-economic and scientific-technical aspects. Regulation of nuclear and radiation safety. Coll. aut. Moscow: MGOF «Znanie», Scientific and Engineering Centre for Nuclear and Radiation Safety, 2003. 400 p. (in Russian)].

[3] Санитарные правила обращзения с радиоактивными отходами (СПОРО-2002). СП 2.6.6.1168-02. СПб: Деан, 2003. 64 c. [Sanitary rules for radioactive waste management (SPORO-2002). SP 2.6.6.1168-02. SPb: Dean, 2003. 64 p. (in Russian)].

$$
-727-
$$


[4] Объединенная конвенщия о безопасности обращения с отработавшим топливом и безопасности обращения с радиоактивными отходами. Вена, 05.09.1997. Конвенция вступила в силу для России 19.04.2006 [Joint Convention on the Safety of Spent Fuel Management and on the Safety of Radioactive Waste Management. Vienna, 05.09.1997. The convention has come into force for Russia 04.19.2006 (in Russian)]. Access: http://www.bellona.ru/Casefiles/vienna97

[5] Конвенция о ядерной безопасности. Вена, 17.06.1994. Конвенция вступила в силу для России 24.10.1996 [Convention On Nuclear Safety. Vienna, 17.06.1994. The convention has come into force for Russia 24.10.1996 (in Russian)]. Access: http://www.bellona.ru/Casefiles-/vienna94

[6] Ключников А.А., Пазухин Э.М., Шигера Ю.М., Шигера В.Ю. Радиоактивные отходы АЭС и методы обращения с ними; ред. Ю.М. Шигера, Киев: Чернобыль, 2005. 496 с. [Klyuchnikov A.A., Pazukhin E.M., Shiger Yu.M., Shiger V.Yu. Radioactive waste from nuclear power plants and methods of handling them; edited by Yu.M. Shiger, Kiev: Chernobyl, 2005. 496 p. (in Russian)].

[7] Лебедев В.М. Ядерный топливный иикл, М.: Энергоатомиздат, 2005. 305 с. [Lebedev V.M. Nuclear Fuel Cycle, M.: Energoatomizdat, 2005. 305 p. (in Russian)].

[8] Волков В.Г., Чесноков А.С. Радиоактивные отходы: хранение и переработка. Промылиленные ведомости, 2011, 11-12 [Volkov V.G., Chesnokov A.S. Radioactive waste: storage and processing. Industrial sheets, 2011, 11-12 (in Russian)].

[9] Милютин В.В., Гелис В.М. Современные методы очистки жидких радиоактивных отходов и радиоактивно-загрязненных природных вод, М.: ИФХЭ РАН, 2011. [Milyutin V.V., Gelis V.M. Modern methods of purification of liquid radioactive wastes and radioactive contaminated natural waters, M.: IPCE RAS, 2011 (in Russian)].

[10] Кулагина Т.А., Кулагин В.А., Матюшенко А.И. Техносферная безопасность в ядерной энергетике, Красноярск: Изд-во «Гротеск», СФУ, 2014, 286 с. [Kulagina T.A., Kulagin V.A., Matyushenko A.I. Technospheric security in nuclear power, Krasnoyarsk: Izd-vo "Grotesque", SFU, 2014, 286 p. (in Russian)].

[11] Кулагина Т.А., Козин О.А., Матюшенко А.И. Экологическая безопасность техносферных объектов, Красноярск: Изд-во «Гротеск», 2015, 323 с. [Kulagina T.A., Kozin O.A., Matyushenko A.I. Environmental safety of technospheric objects, Krasnoyarsk: Izd-vo "Grotesque", 2015, 323 p. (in Russian)].

[12] Кулагин В.А., Кулагина Т.А., Матюшенко А.И. Переработка отработавшего ядерного топлива и обращение с радиоактивными отходами. Журнал СФУ. Техника и технологии, 2013, 6(2), 123-149 [Kulagin V.A., Kulagina T.A., Matushenko A.I. Spent Fuel Reprocessing and Radioactive Waste Management. J. Sib. Fed. Univ. Eng. Technol, 2013, 6(2), 123-149 (in Russian)].

[13] Todd T. Introduction to Nuclear Fuel Cycle Separations: CRESP Short Course - Introduction to Nuclear Fuel Cycley Chemistry. Crystal City, VA, August 4, 2009.

[14] Starks J.B. Purex process. United States, 1977. Access: http://www.osti.gov/scitech/ biblio/5220059

[15] Тананаев И.Г., Мясоедов Б.Ф. Химическое поведение плутония в щелочных отходах: формы существования, редокс-реакиии и структурные превращения, М.: Институт геохимии и аналитической химии РАН им. В.И. Вернадского, 2002. 356 с. [Tananaev I.G., Myasoedov B.F. Chemical behavior of Plutonium in alkaline waste: forms of existence, redox-reactions and structural 
transformations, M.: Institute of Geochemistry and Analytical Chemistry, Russian Academy of Sciences V.I. Vernadsky, 2002. 356 p. (in Russian)].

[16] Касаткин А.Г. Основные процессы и аппараты химической технологии, М.: Химия, 1973. 750 c. [Kasatkin A.G. Basic processes and apparatuses of chemical technology. M.: Chemistry, 1973. 750 p. (in Russian)].

[17] Кулагина Т.А., Попков В.А. Метод обращения с отходами ядерного топлива в атомной энергетике. Журнал СФУ. Техника и технологии, 2015, 8(2), 198-207 [Kulagina T.A., Popkov V.A. Method of Handling Nuclear Waste in Nuclear Power Engineering. J. Sib. Fed. Univ. Eng. Technol, 2015, 8(2), 198-207 (in Russian)].

[18] Кулагина Т.А., Попков В.А. Влияние кавитационно активированной воды на характеристики цементного компаунда. Журнал СФУ. Техника и технологии, 2015, 8(3), 362-368 [Kulagina T.A., Popkov V.A. Influence of Kavitatsionno Activated Water on Characteristics Cement Compound. J. Sib. Fed. Univ. Eng. Technol, 2015, 8(3), 362-368 (in Russian)].

[19] Ермолаев В.М., Захарова Е.В., Мироненко М.В. Изменение состава и свойств радиоактивных пульп в процессе длительного хранения в емкостях. Радиохимия, 2006, 47(3), 374-379 [Ermolaev V.M., Zaharova E.V., Mironenko M.V. Evolution of composition and properties of radioactive pulps in long-term storage in tanks. Radiochemistry, 2006, 47(3), 374-379 (in Russian)].

[20] Шилов В.П., Федосеев А.М. Растворимость Pu(IV) в слабощелочных средах (pH 9-14) в присутствии силикат ионов. Радиохимия, 2003, 45(5), 441-444 [Shilov V.P., Fedoseev A.M. Solubility of $\mathrm{Pu}(\mathrm{IV})$ in alkalescent environments ( $\mathrm{pH} 9-14)$ at presence of silicate ions. Radiochemistry, 2003, 45 (5), 441-444 (in Russian)].

[21] Кулагина Т.А., Кулагин В.А., Москвичев В.В., Попков В.А. Применение кавитационной технологии в процессах обращения с отработавшим ядерным топливом. Экология и промышленность России, 2016, 20(10), 4-10 [Kulagina T.A., Kulagin V.A., Moskvichev V.V., Popkov V.A. The Use of Cavitation Technology in the Treatment of Spent Nuclear Fuel Processes. Ecology and Industry of Russia, 2016, 20(10), 4-10 (in Russian)].

[22] Kulagina T.A., Kulagin V.A., Popkov V.A. Compounding of spent nuclear fuel. J. Sib. Fed. Univ. Eng. Technol, 2016, 9(2), 280-295.

[23] Кулагина Т.А., Попков В.А. Подготовка радиоактивных отходов к длительному хранению (захоронению) с помощью цементных компаундов. Журнал СФУ. Техника и технологии, 2015, 8(7), 917-927 [Kulagina T.A., Popkov V.A. Preparation of Radioactive Waste to Long Storage (Burial) Using of the Cement Compound J. Sib. Fed. Univ. Eng. Technol, 2015, 8(7), 917-927 (in Russian)].

[24] Алой А.С. Аналитическая справка о методах обращения с альфа-содержащчими РАO, СПб., 2016. 34 с. [Aloy A.S. Analytical reference on methods of handling alpha-containing radioactive waste, St. Petersburg, 2016. 34 p. (in Russian)].

[25] Технологические и организационные аспекты обращения с радиоактивными отходами. МАГАТЭ, IAEA-TCS-27, ISSN 1018-5518, BEHA, 2005. 230 c. [Technological and organizational aspects of radioactive waste management. International Atomic Energy Agency, IAEA-TCS-27, ISSN 1018-5518, Vienna, 2005. 230 p. (in Russian)].

[26] НП-019-2015 Сбор, переработка, хранение и кондиционирование жидких радиоактивных отходов. Требования безопасности. Москва, 2015. 13 с. [NP-019-2015 Collecting, processing, 
storage and conditioning of liquid radioactive waste. Safety requirements. Moscow, 2015. 13 p. (in Russian)].

[27] Ястребинский Р.Н., Павленко В.И., Карнаухов А.В., Ястребинская А.В. Радиационная стойкость радиационно-защитных железооксидных композитов в $\gamma$-полях. Bопросы атомной науки и техники, 2013, 2, 46-49 [Yastrebinsky R.N., Pavlenko V.I., Karnaukhov A.V., Yastrebinskaya A.V. Radiation resistance radiation-defensive the ferrous aggregates in the gamma fields. Questions of atomic science and technology, 2013, 2, 46-49 (in Russian)].

[28] Отраслевые правила ядерной безопасности для заводов типа «Б» и «ДБ». Москва, 1993. 36 c. [Industry rules of nuclear safety for the plants like " $B$ " and " $D B$ ". Moscow, 1993. 36 p. (in Russian)].

[29] Внуков В.С., Сичкарук О.В., Чкуасели Л.И. Ядерная безопасность при обращении с PAO. Атомная стратегия, 2004, 13, 1-6 [Vnukov V.S., Sichkaruk O.V., Chkuaseli L.I. Nuclear safety in the management of radioactive waste. Atomic Strategy, 2004, No. 13, 1-6 (in Russian)].

[30] Ежков B.О., Ежкова А.М., Яппаров А.Х. Технология использования бентонитовых глин в качестве сорбентов солей тяжельх металлов из организма животных в регионах техногенной нагрузки Республики Татарстан, БИБКОМ, 2013. 100 c. [Ezhkov V.O., Ezhkov A.M., Yapparov A.Kh. The technology of using bentonite clays as sorbents of heavy metal salts from animals in the regions of technogenic load of the Republic of Tatarstan, BIBCOM, 2013. 100 p. (in Russian)].

[31] Бетехтин А.Г. Курс минералогии, М.: Гос. Изд-во геолог. лит-ры, 1951. 543 с. [Betekhtin A.G. Course of Mineralogy, Moscow: Gos. Izd-vo geologist. lit-ry, 1951. 543 p. (in Russian)].

[32] Ивченко В.М., Кулагин В.А., Немчин А.Ф. Кавитационная технология; ред. акад. Г.В. Логвинович, Красноярск: Изд-во КГУ, 1990. 200 с. [Ivchenko V.M., Kulagin V.A., Nemchin A.F. Cavitation technology; edited by academician G.V. Logvinovich, Krasnoyarsk: Izd-vo KGU, 1990. 200 p. (in Russian)].

[33] Демиденко Н.Д., Кулагин В.А., Шокин Ю.И., Ли Ф.-Ч. Тепломассообмен и суперкавитация, Новосибирск: Наука, 2015. 436 с. [Demidenko N.D., Kulagin V.A., Shokin Yu.I., Lee F.-C. Heat and mass transfer and supercavitation, Novosibirsk: Nauka, 2015. 436 p. (in Russian)].

[34] An Chart of Nuclides, Nuclides 2000, Version 1.00, European Communities, 1999, 88 p.

[35] Ермолаев В.М., Захарова Е.В., Мироненко М.В. Изменение состава и свойств радиоактивных пульп в процессе длительного хранения в емкостях. Радиохимия, 2006, 48(3), 301-306 [Ermolaev V.M., Zaharova E.V., Mironenko M.V. Evolution of composition and properties of radioactive pulps in long-term storage in tanks. Radiochemistry, 2006, 48(3), 301-306 (in Russian)].

[36] Кулагин В.А. Суперкавитационный миксер, Гидродинамика больших скоростей: межвузовский сборник; ред. В.А. Кулагин. Красноярск, КПИ, 1992, 134-140 [Kulagin V.A. Supercavitational mixer, High-speed hydrodynamics: interuniversity collection, edition V.A. Kulagin. Krasnoyarsk, KPI, 1992, 134-140 (in Russian)].

[37] Кулагин В.А., Сапожникова Е.С., Стебелева О.П. Особенности влияния эффектов кавитации на физико-химические свойства воды и стоков. Журнал СФУ. Техника и технологии, 2014, 7(5), 605-614 [Kulagin V.A., Sapoghnikova E.S., Stebeleva O.P. Features of Influence of Cavitation Effects on the Physicochemical Properties of Water and Wastewater, J. Sib. Fed. Univ. Eng. technol. 2014, 7(5), 605-614 (in Russian)]. 
[38] Кулагин В.А. Методы и средства технологической обработки многокомпонентных сред с использованием эффектов кавитачии, дис. ... д-ра техн. наук. Красноярск, 2004. 406 с. [Kulagin V.A. Methods and means of technological processing of multicomponent media using the effects of cavitation, dis. ... Dr. techn. sciences. Krasnoyarsk, 2004. 406 p. (in Russian)].

[39] Маргулис М.А. Звукохимические реакции и сонолюминесценция, М.: Химия, 1986. 288 c. [Margulis M.A. Sound chemical reactions and sonoluminescence, Moscow: Chemistry, 1986. 288 p. (in Russian)].

[40] Королев Е.В., Самошин А.П., Смирнов В.А. и др. Методики и алгоритм синтеза радиационно-защитных материалов нового поколения, Пенза: ПГУАС, 2009. 130 c. [Korolev E.V., Samoshin A.P., Smirnov V.A. and others. Techniques and algorithm for the synthesis of radiationprotective materials of a new generation, Penza: PGUAS, 2009. 130 p. (in Russian)].

[41] Cwirzen A. et al. Properties of high yield synthesised carbon nano fibres/Portland cement composite. Advances in Cement Research, 2009, 21, 141-146.

[42] Хозин В.Г., Старовойтова И.А., Майсурадзе Н.В. Наномодифицирование полимерных связующих для конструкционных композитов. Строительные материаль, 2013, 2, 4-10 [Khozin V.G., Starovoitova I.A., Maisuradze N.V. Nanomodification of polymer binders for constructional composites. Construction Materials, 2013, 2, 4-10 (in Russian)].

[43] Пухаренко Ю.В., Аубакирова И.У., Никитин В.А., Староверов В.Д. Структура и свойства наномодифицированных цементных систем, Материаль Международного конгресса «Наука и инновачии в строительстве «SIB-2008»». Современные проблемы строительного материаловедения и технологии. Воронеж, 2008, 1(2), 424-429 [Pukharenko Yu.V., Aubakirova I.U., Nikitin V.A., Staroverov V.D. Structure and properties of nanomodified cement systems, Materials of the International congress "Science and innovations in construction of "SIB-2008",'. Modern problems of construction materials science and technology. Voronezh, 2008, 1(2), 424-429 (in Russian)].

[44] Пул Ч., Оуэнс Ф. Нанотехнологии, М.: Техносфера, 2006. 336 c. [Poole C., Owens F. Nanotechnology, M.: Technosphere, 2006. 336 p. (in Russian)].

[45] Castrillon M., Garcia C., Paucar C. Evaluation of the influence of the particle size and the time of thermal treatment on the physical-mechanical characteristics of a composite of sinterized alumina infiltrated with a lanthanum glass. Dyna Medellin Colombia. 2007, 152. P. 159-165. 